\title{
Erratum to: Application of PCM thermal energy storage system to reduce building energy consumption
}

Jisoo Jeon · Jeong-Hun Lee · Jungki Seo •

Su-Gwang Jeong • Sumin Kim

Published online: 6 April 2012

(C) Akadémiai Kiadó, Budapest, Hungary 2012

Erratum to: J Therm Anal Calorim

DOI 10.1007/s10973-012-2291-9

Unfortunately the second author's name had been misspelled in the original publication of this article. The correct version is Jeong-Hun Lee.

The online version of the original article can be found under doi:10.1007/s10973-012-2291-9.

J. Jeon · J.-H. Lee $\cdot$ J. Seo $\cdot$ S.-G. Jeong $\cdot$ S. Kim $(\bowtie)$

Building Environment \& Materials Lab, School of Architecture,

Soongsil University, Seoul 156-743, Republic of Korea

e-mail: skim@ssu.ac.kr 